\title{
Development of Contact Lens Suitability System (ClenSyst)
}

\author{
Syaratul Ain Muhammed Hafiz ${ }^{\mathrm{a}}$, Noraidah Sahari @ Ashaari ${ }^{\mathrm{b}}$, Jemaima Che Hamzah ${ }^{\mathrm{c}}$, Syariza Razak ${ }^{\mathrm{d}}$ \\ ${ }^{a, b}$ Department Technology and Science Information \\ National University of Malaysia \\ Fakulti Teknologi dan Sains Maklumat (FTSM) \\ Universiti Kebangsaan Malaysia, 43600 Bandar Baru Bangi \\ Malaysia \\ $\mathrm{Tel}: 012-8294585$ \\ sya_ein@yahoo.com \\ c.d Department of Ofthalmology \\ National University of Malaysia Hospital (HUKM) \\ Universiti Kebangsaan Malaysia, 56000 Cheras Kuala Lumpur \\ Malaysia \\ $\mathrm{Tel}: 013-3986612$ \\ jemaimac@yahoo.com
}

\begin{abstract}
This paper proposes a system that can determine the suitability of contact lenses usage. The aim of this work is to provide a decision making system by using the application of fuzzy logic to analyze and decide the appropriate type of contact lenses based on the corneal condition, astigmatism, reason and environment of the patient. A corneal topography is used to give information on corneal power and astigmatism measurement. The expected output of the system is suitability of using contact lenses, corneal power and the type of contact lens.
\end{abstract}

\section{Keywords:}

Fuzzy logic, Decision System Support, Contact lens, Corneal Topography

\subsection{INTRODUCTION}

The aim of this work is to provide a system that can analyze and to decide the suitability and appropriate type of contact lenses based on the corneal condition. The development of decision making system is focused on evaluating the data given from corneal topography using fuzzy model.

Measurement of shape, refractive power and the thickness of the cornea are very important for designing vision correction surgeries and diagnosing corneal diseases (Liu, Huang, Pflugfelder, 1998). Diagnostic equipment used for determination of corneal condition that fit with contact lenses is Corneal Topographer. This tool is a computer linked to a lighted bowl with a pattern of concentric rings inside it. Of all the technology currently available, corneal topography provides the most detail information about the curvature of the cornea and the information given is useful to evaluate and correct astigmatism, monitor corneal disease and detect irregularities in the corneal shape (Gills, 2002).

In this study the decision support system and fuzzy logic concept are used in order to determine the appropriate contact lens according to the ocular refractive errors. In early 1978, Keen and Scott-Morton said, decision support system couples the intellectual resources of individuals with the capabilities of the computer to improve the quality of decisions. Fuzzy logic is an application that includes calculation that is undecided, and it is used to build up one or two parameter. The use of fuzzy logic for creating decision-support has grown in popularity among decision-modeling experts (Keen, 1975).

The structure of the paper is as follows: introduction of term used in this research elaborated in introduction section. Section 2 discusses the introduction of system proposed using decision support system. Section 3 shows the fuzzy model developments and some brief discussion of the approach used and section 4 provides some conclusion at the end of paper.

\subsection{Ocular refractive error}

A condition in which the eye exhibits a difficulty in focusing the image in retina is generically named as ametropia, or refractive error. Blurred vision, eye discomfort and occasionally headaches are the symptoms cause by refractive error that usually can be corrected using contact lenses or glasses that compensate for them. The three major types of refractive errors are myopia, hypermetropia and astigmatism (Kellogg Eye Center, 2008). However, contact lenses were prescribed to correct focus error only, but not for astigmatism correction ( $\mathrm{Lu}, \mathrm{Mao}, \mathrm{Qu}, \mathrm{Xu}, \mathrm{He}, 2003)$.

Myopia is a disturbance in image focusing that causes the image to be formed before the retina and prevent one from 
seeing distant object clearly and the object appear blurred. Opposite to myopia, hyperopia focusing error behind the retina, thus preventing a clear focalization of near object.

Astigmatism is shown when the corneal surface is oval like rugby ball instead of spherical. This indicates the light focuses on more than one point in eyes, resulting in blurred vision at the distance and near. Astigmatism often occurs along with myopia and hyperopia. Patient with astigmatism will faced blurred vision and it can be treated with glasses, contact lenses or surgical.

Table 1 illustrates mild to severe shortsightedness and mild to severe longsightedness and the measurement of ocular refractive error.

Table 1 : Type and measurement of ocular refractive error

\begin{tabular}{|c|c|}
\hline Type of ocular refractive error & Dioptres \\
\hline Mild shortsightedness & Myopia up to $-3.00 \mathrm{D}$ \\
\hline Low shortsightedness & $\begin{array}{c}\text { Myopia up to }-3.25 \mathrm{D} \text { to } \\
-6.00 \mathrm{D}\end{array}$ \\
\hline Moderate shortsightedness & $\begin{array}{c}\text { Myopia up to }-6.25 \mathrm{D} \text { to } \\
-11.00 \mathrm{D}\end{array}$ \\
\hline Severe shortsightedness & $\begin{array}{c}\text { Myopia up to }-11.25 \mathrm{D} \text { to } \\
-23.5 \mathrm{D}\end{array}$ \\
\hline Low longsightedness & $\begin{array}{c}\text { Hyperopia from }+0.75 \mathrm{D} \text { to } \\
+2.5 \mathrm{D}\end{array}$ \\
\hline Moderate longsightedness & $\begin{array}{c}\text { Hyperopia from }+2.75 \text { to } \\
+6.00 \mathrm{D}\end{array}$ \\
\hline Severe longsightedness & $\begin{array}{c}\text { Hyperopia from }+6.25 \mathrm{D} \text { to } \\
+12.00 \mathrm{D}\end{array}$ \\
\hline
\end{tabular}

Dioptres (D) is the amount of correction to be done to get a normal vision. One dioptres equivalent of a lens that can focus on an object one meter away. If patients above six dioptres (normal vision dioptres), it is still worth while coming for a consultation. The doctors may advice the patient to give less dependence on glasses and contact lenses, or outline other treatment options available (Steele, 1992).

\subsection{Contact Lenses}

The purpose of contact lens is to correct refractive error of an eye to improve the optical quality of the retinal image, thereby improving vision (Hong, Himebaugh, Thibos, 2001). Contact lenses are thin, curved plastic disks designed to cover the cornea, the clear front covering of the eye and used to correct the same conditions that eyeglasses correct: myopia (nearsightedness), hyperopia (farsightedness), astigmatism (distorted vision) and presbyopia (need for bifocals).

\subsection{Corneal Topography}

Measurement of shape, refractive power and the thickness of the cornea are very important for designing vision correction surgeries and diagnosing corneal disease (Liu,, Zhang, Chen, Luo, Chen, Gong, Huang, Lin Y, Wang, 2002). This equipment gives a series of printouts of the cornea shape by creating topography map called corneal map. Corneal map reveals the topography or shape of corneal surface. A familiar analogy is a topographical land map, which uses a series of wavy lines to show the surface characteristic of a track of a land. Each color in the corneal map giving different information on dioptic values (the unit of measurement used to express the power of cornea and eyes). Figure 1 show the printed out corneal data from corneal topography.

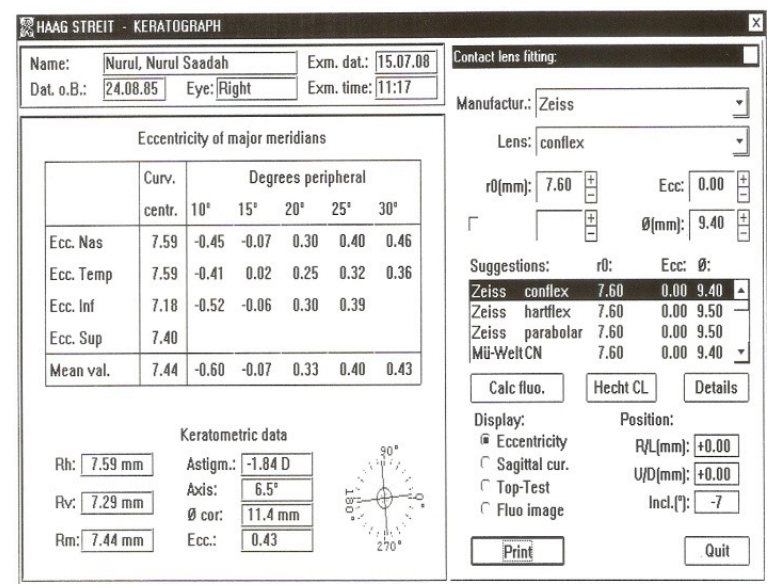

Figure 1 : Corneal topography data.

\subsection{Fuzzy Logic and Decision Support System}

Fuzzy logic is a generalization of classical logic which there is a smooth transition from true to false. In addition to symbol manipulation, it uses numeric computation to facilitate approximate reasoning (Arafeh \& Singh, 1999) while Negnevitsky (2005) said that fuzzy logic is the theory of fuzzy sets, sets that calibrate vagueness. Fuzzy logic is based on the idea that all things limit to degrees and based on the simple rules, dealing with uncertainties and it is easy to apply and take less time.

Fuzzy logic concept is the combination of the intelligent system and decision support. This characteristic makes this system gives the accurate analysis. There is two important aspect, knowledge representative and decision making. The application of fuzzy logic in decision system support (DSS) was done by Metaxiotis, discuss about the latest and future prospect in term of integrating fuzzy logic into DSS. Decision support systems (DSS) are computer technology solutions that can be used to support complex decision making and problem solving. DSS have evolved from two main areas of research - the theoretical studies of organizational decision making. Fuzzy logic is one of the concepts in artificial intelligence which can resolve the uncertainty concept. In this paper by Metaxiotis, Psarras and Samouilidis also discuss about the other application of fuzzy logic in DSS (Metaxiotis,, Psarras, Samouilidis, 2003). 
Garavelli,, Gorgoglione, Scozzi (1999) applied the fuzzy logic in DSS to improve the robustness of DSS under uncertainty. By comparing fuzzy logic method and weighting method, thus found out that fuzzy logic is more sensitive to detect cases in waste management data.

\subsection{CONTACT LENS SYSTEM (ClenSyst)}

In this research, we use the application of fuzzy logic to determine the suitability and type of contact lenses. Criteria for the suitability are dry eyes, allergy, flappy eyes, ages, eye diseases and contact lens user's reason and environment. The 'reason' criteria are divided into some parameters. Corneal topographer data is taken from the vertical and the horizontal of the cornea to calculated the corneal power in order to determine the power in cornea only. The architecture of the system mentioned is describe as in Figure 2.

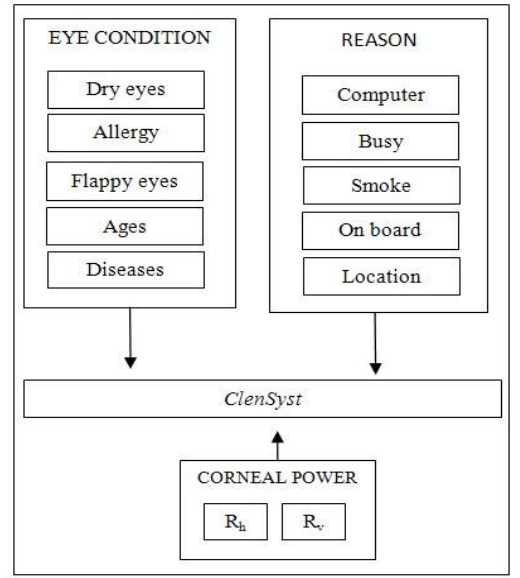

Figure 2: Architecture of the system for contact lenses determination suitability.

The evaluation of each criteria given by the domain expert in ophthalmology. Table 2 shows the category and range for each criteria.

Table 2 : Criteria for ClenSyst

\begin{tabular}{|c|c|c|c|c|c|c|}
\hline \multirow{2}{*}{$\begin{array}{l}\text { Variabl } \\
\text { es }\end{array}$} & \multicolumn{2}{|c|}{ Category 1} & \multicolumn{2}{|c|}{ Category 2} & \multicolumn{2}{|c|}{ Category 3} \\
\hline & $\begin{array}{l}\text { Range } \\
\text { value }\end{array}$ & Label & $\begin{array}{l}\text { Range } \\
\text { value }\end{array}$ & Label & $\begin{array}{l}\text { Range } \\
\text { value }\end{array}$ & Label \\
\hline $\begin{array}{c}\text { Dry } \\
\text { eyes } \\
\left(x_{1}\right) \\
\end{array}$ & $\begin{array}{c}0 \leq \mathrm{x}_{1} \leq \\
\mathrm{T}_{x l}{ }^{I}\end{array}$ & Low & $\begin{array}{c}0 \leq \mathrm{x}_{1} \leq \\
\mathrm{T}_{x l^{2}}{ }^{2}\end{array}$ & $\begin{array}{c}\text { Moder } \\
\text { ate }\end{array}$ & $\begin{array}{c}0 \leq \mathrm{x}_{1} \leq \\
\mathrm{T}_{x l}{ }^{3}\end{array}$ & Severe \\
\hline $\begin{array}{c}\text { Allergy } \\
\left(x_{2}\right)\end{array}$ & $\begin{array}{c}0 \leq \mathrm{x}_{1} \leq \\
\mathrm{T}_{x 2} I \\
\end{array}$ & Low & $\begin{array}{c}0 \leq \mathrm{x}_{1} \leq \\
\mathrm{T}_{x 2}{ }^{2} \\
\end{array}$ & $\begin{array}{c}\text { Moder } \\
\text { ate }\end{array}$ & $\begin{array}{c}0 \leq \mathrm{x}_{1} \leq \\
\mathrm{T}_{x 2}{ }^{3} \\
\end{array}$ & Severe \\
\hline $\begin{array}{c}\text { Flappy } \\
\text { eye } \\
\left(x_{3}\right) \\
\end{array}$ & $\begin{array}{c}0 \leq \mathrm{x}_{1} \leq \\
\mathrm{T}_{x 3^{3}}{ }^{3}\end{array}$ & Slow & $\begin{array}{c}0 \leq \mathrm{x}_{1} \leq \\
\mathrm{T}_{x 3^{2}}{ }^{2}\end{array}$ & Normal & $\begin{array}{c}0 \leq \mathrm{x}_{1} \leq \\
\mathrm{T}_{x 3^{3}}{ }^{3}\end{array}$ & Rapid \\
\hline $\begin{array}{c}\text { Ages } \\
\left(x_{4}\right)\end{array}$ & $\begin{array}{c}0 \leq \mathrm{x}_{1} \leq \\
\mathrm{T}_{x 4}{ }^{I}\end{array}$ & Child & $\begin{array}{c}0 \leq \mathrm{x}_{1} \leq \\
\mathrm{T}_{x 4}{ }^{2}\end{array}$ & Young & $\begin{array}{c}0 \leq \mathrm{x}_{1} \leq \\
\mathrm{T}_{x 4}{ }^{3}\end{array}$ & Old \\
\hline $\begin{array}{c}\text { Disease } \\
\mathrm{S}\end{array}$ & $\begin{array}{c}0 \leq \mathrm{x}_{1} \leq \leq \\
\mathrm{T}_{x S^{1}}{ }^{1} \\
\end{array}$ & $\begin{array}{c}\text { Modera } \\
\text { te }\end{array}$ & $\begin{array}{c}0 \leq \mathrm{x}_{1} \leq \leq \\
\mathrm{T}_{x 5^{2}}{ }^{2}\end{array}$ & Normal & $\begin{array}{c}0 \leq \mathrm{x}_{1} \leq \\
\mathrm{T}_{x 5}{ }^{3}\end{array}$ & Severe \\
\hline
\end{tabular}

\section{$\left(x_{5}\right)$}

All the criteria evaluated using fuzzy logic method. The fuzzy model added in the basic decision support system as one of the component. Basic decision support system component are database management software (DBMS), model based management software (MBMS) and dialog generation and management software (Sprague \& Carlson, 1983). This system will give the expected output of corneal power, suitability and the suitable type of contact lenses.

\subsection{FUZZY MODEL}

In this system, fuzzy model developed by determine the fuzzy operation, fuzzy rule-based operation and fuzzy inference.

Fuzzy operation divided into two step, input and output variables and linguistic values definition. The next step is to define the fuzzy membership. The knowledge based in this system is determined by domain expert in ophthalmology. The input variables used in rules are dry eyes, allergy, flappy eyes, ages, eye diseases and contact lens user's reason of wearing contact lenses. This is the important criteria to decide whether a person is suitable to use contact lens.

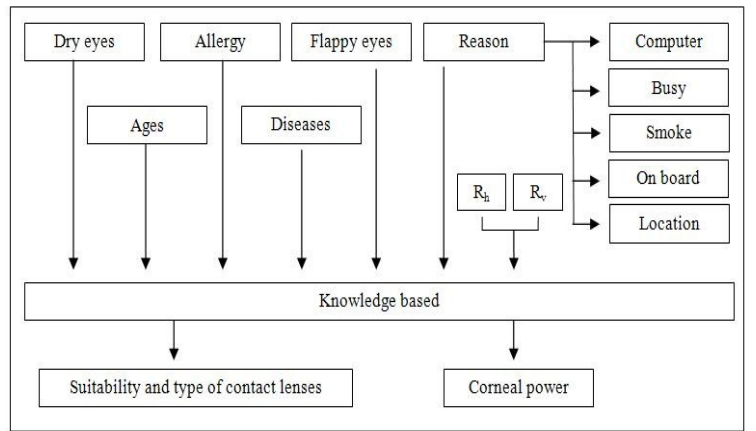

Figure 3 : Fuzzy input and output variables

Given the fuzzy input variables is dry eyes $\left(x_{1}\right)$, allergy $\left(x_{2}\right)$, flappy eyes $\left(x_{3}\right)$, ages $\left(x_{4}\right)$, eye diseases $\left(x_{5}\right)$ and contact lens user's reason $\left(x_{6}\right)$. Show that user's reason $\left(x_{6}\right)$ have own membership values that have to be determined before calculated with others. $\mathrm{T}\left(x_{i}\right)$ is linguistic term set for $x_{i}$ variables $(i=1,2, \ldots 3)$. For example, the linguistic term set for $\mathrm{T}\left(x_{1}\right)$ given by

$$
\mathrm{T}\left(x_{1}\right)=\left\{\mathrm{T}_{x l}^{1}, \mathrm{~T}_{x l}^{2}, \mathrm{~T}_{x l}^{3}\right\}
$$

with linguistic values 'low', 'moderate' and 'severe'. Table 2 show the input variable for $x_{1}, x_{2}, x_{3}, x_{4}$ and $x_{5}$ and table 3 show input variable for $x_{6}$.

Table $3: x_{1}, x_{2}, x_{3}, x_{4}$ and $x_{5}$ input variables declarations. 


\begin{tabular}{|c|c|c|c|}
\hline \multirow{2}{*}{ Input variables } & \multicolumn{3}{|c|}{ Term set } \\
\cline { 2 - 4 } & $\mathrm{T}_{x i}{ }^{1}$ & $\mathrm{~T}_{x i}{ }^{2}$ & $\mathrm{~T}_{x i}{ }^{3}$ \\
\hline $\begin{array}{c}\text { Dry eyes } \\
\left(x_{1}\right)\end{array}$ & Low & Moderate & Severe \\
\hline $\begin{array}{c}\text { Allergy } \\
\left(x_{2}\right)\end{array}$ & Low & Moderate & Severe \\
\hline $\begin{array}{c}\text { Flappy eye } \\
\left(x_{3}\right)\end{array}$ & Slow & Normal & Rapid \\
\hline $\begin{array}{c}\text { Ages } \\
\left(x_{4}\right)\end{array}$ & Child & Young & Old \\
\hline $\begin{array}{c}\text { Diseases } \\
\left(x_{5}\right)\end{array}$ & Moderate & Normal & Severe \\
\hline
\end{tabular}

(where $i=1,2 \ldots$ and 5 )

Table $4: x_{6}$ input variable declarations

\begin{tabular}{|c|c|c|c|}
\hline \multirow{2}{*}{ Input variables } & \multicolumn{3}{|c|}{ Term set } \\
\cline { 2 - 4 } & $\mathrm{T}_{x i}{ }^{l}$ & $\mathrm{~T}_{x i}{ }^{2}$ & $\mathrm{~T}_{x i}{ }^{3}$ \\
\hline $\begin{array}{c}\text { computer } \\
\left(x_{1}\right)\end{array}$ & Low & Moderate & allTime \\
\hline $\begin{array}{c}\text { busy } \\
\left(x_{2}\right)\end{array}$ & notBusy & Moderate & Busy \\
\hline $\begin{array}{c}\text { smoke } \\
\left(x_{3}\right)\end{array}$ & Moderate & Normal & Heavy \\
\hline $\begin{array}{c}\text { flight } \\
\left(x_{4}\right)\end{array}$ & Occasionally & Moderate & Always \\
\hline $\begin{array}{c}\text { location } \\
\left(x_{5}\right)\end{array}$ & Cold & Normal & Hot \\
\hline
\end{tabular}

(where $i=1,2 \ldots$ and 5).

The measurement of corneal power will be given in dioptres values. Given from corneal topography is the astigmatism power and $R_{v}$ and $R_{h}$ values which the corneal power given by the equation (2).

$$
\text { Corneal power }=\frac{\mathrm{R}_{\mathrm{v}}+\mathrm{R}_{\mathrm{h}}}{2}
$$

To define the fuzzy membership, triangle shape provides enough expert knowledge representatives and in the mean time can make the calculation easier (Negnevitsky, 2005). The intersect point $\left(S_{i j}\right)$ between two set of input variable $\left.\left(a_{i}, a_{j}, b_{i}, b_{j}, c_{i}, c_{j},\right)\right)$ term can be calculated using the given equation (3). The illustration of the intersect presented in graph shown by figure 4 .

$$
S_{i j}=\frac{(b a)-(b c)}{(b-b)+(a-c)}
$$

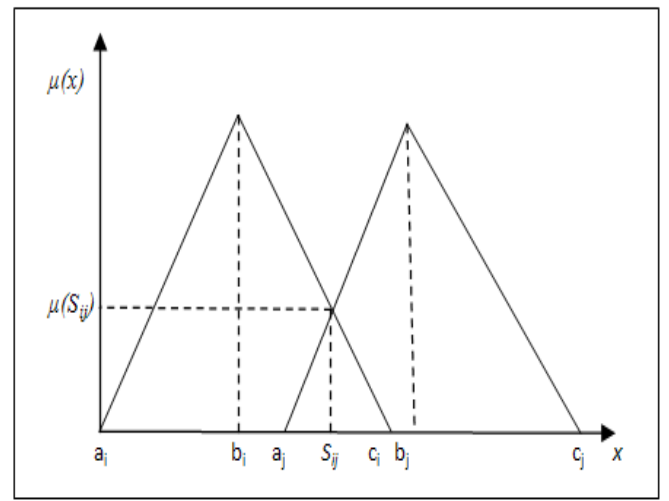

Figure 4 : Intersect point $\left(\mathrm{S}_{\mathrm{ij}}\right)$ between two set of input variable term.

Table 5 shows the declaration of linguistic term set and values, numerical values, intersect point and membership graph for $\mathrm{T}_{\mathrm{x} 1}$ as an example for input variables.

\begin{tabular}{|c|c|c|c|}
\hline \multirow{2}{*}{ Dry eyes $\left(x_{l}\right)$} & \multicolumn{3}{|c|}{ Term set } \\
\hline & $\mathrm{T}_{x i}{ }^{l}$ & $\mathrm{~T}_{x i}{ }^{l}$ & $\mathrm{~T}_{x i}{ }^{3}$ \\
\hline Linguistic values & Low & Moderate & Severe \\
\hline $\begin{array}{c}\text { Numerical values } \\
{\left[a_{i}, b_{i}, c_{i}\right]}\end{array}$ & {$[0.0,0.0,50]$} & {$[0.0,50,100]$} & {$[50,100,100]$} \\
\hline $\begin{array}{c}\text { Membership } \\
\text { graph } \\
\text { Intersect point: } \\
\text { low_moderate } \\
25 \\
\text { moderate_severe } \\
75\end{array}$ & \begin{tabular}{l|l}
1 & \\
0.8 \\
0.6 \\
0.4 \\
0.2 \\
0 \\
0 \\
0
\end{tabular} & 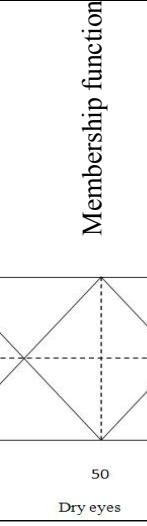 & $V_{100}$ \\
\hline
\end{tabular}

Table 5 : Dry eye $\left(\mathrm{x}_{1}\right)$ variable declarations

Fuzzy rule-based phase is presenting the variable linguistic values to fuzzy rules using AND operator to connect respective input and output variables as given equation (4).

$R_{j}$ : IF $x_{i}$ is $A_{k}$ AND $x_{i}$ is $B_{k}$ AND $x_{i}$ is $C_{k}$ AND $x_{i}$ is $\mathrm{D}_{k}$ THEN $y_{i}$ is $E_{l}$.

$R_{j}$ is rules where $\mathrm{j}=1,2 \ldots . \mathrm{n}, x_{i}$ is input variables where $\mathrm{i}=1,2 \ldots$ $n$-th variables and $A_{k}, B_{k}, C_{k}, D_{k}$ is linguistic value for every input variable $x_{i}$ and $j$-th rules $\left(k=1,2 . . n\right.$-th term set). $y_{i}$ is output variables with $E_{l}$ is linguistic value for output variables $(l=1,2 . . n$ term set). Below is the example fuzzy rule: 
If dry eyes $\left(x_{1}\right)$ is moderate And allergy $\left(x_{2}\right)$ is moderate And flappy eyes $\left(x_{3}\right)$ is normal And ages $\left(x_{4}\right)$ is young And eye diseases $\left(x_{5}\right)$ is normal

Then suitability $\left(y_{l}\right)$ is suitable

For fuzzy output variable, term set for suitability $\left(y_{l}\right)$ given by three set of term with value of 'suitable', 'moderate' and 'not suitable'. Equation (5) is the linguistic term set for $\mathrm{T}\left(y_{l}\right)$ The output variable declaration shown in Table 6 .

$$
\mathrm{T}\left(y_{1}\right)=\left\{\mathrm{T}_{y l}{ }^{1}, \mathrm{~T}_{y 1}{ }^{2}, \mathrm{~T}_{y 1}{ }^{3}\right\}
$$

Table $6: y_{1}, y_{2}$ and $y_{3}$ output variables declarations.

\begin{tabular}{|c|c|c|c|}
\hline \multirow{2}{*}{ Output variables } & \multicolumn{3}{|c|}{ Term set } \\
\cline { 2 - 4 } & $\mathrm{T}_{y i}{ }^{l}$ & $\mathrm{~T}_{y i}{ }^{2}$ & $\mathrm{~T}_{y i}{ }^{3}$ \\
\hline $\begin{array}{c}\text { Soft Lens } \\
\left(y_{1}\right)\end{array}$ & Suitable & Moderate & notSuitable \\
\hline $\begin{array}{c}\text { Hard Lens } \\
\left(y_{2}\right)\end{array}$ & Suitable & Moderate & notSuitable \\
\hline
\end{tabular}

Fuzzy inference is the important process in fuzzy system where this is a process of mapping from given input to an output using the theory of fuzzy sets. We use Mamdani-style because its requirement of gaining knowledge from domain expert (Negnevitsky, 2005). There are four steps include: fuzzification of the input variables, rules evaluation, aggregation of the rule outputs and defuzzification.

In fuzzification of the input variables, the system will determine the degree of membership for fuzzy sets using input

given by user. In order to evaluate the conjunction of the rule antecedents, we apply the AND fuzzy operation intersection, shown as below equation (6):

$$
\mu_{\mathrm{AnB}}(\mathrm{x})=\min \left[\mu_{\mathrm{A}}(\mathrm{x}), \mu_{\mathrm{B}}(\mathrm{x})\right]
$$

Result of the antecedent evaluation applied to the membership function of the consequent. The consequent membership function is clipped to the level of the truth value of the rule antecedent. Since the top of the membership function is sliced, the clipped fuzzy set loses some information. However it involves less complex and generates an aggregated output surface that is easier to defuzzify. Clipped and scaled membership functions are illustrated in figure 4.

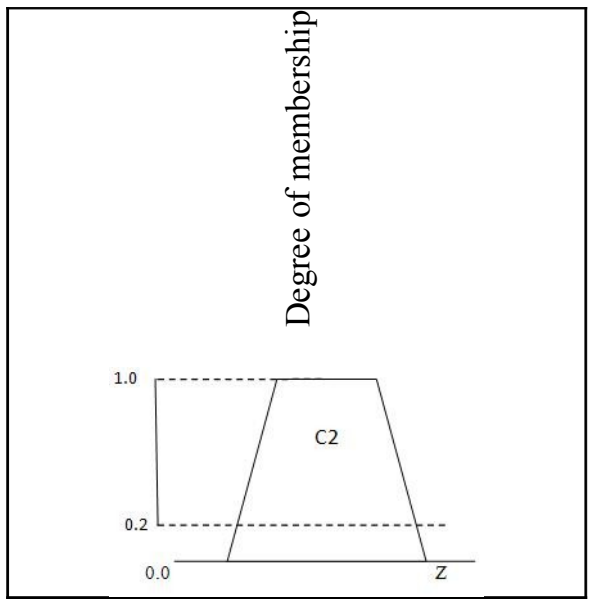

Figure 5 : Clipped membership functions

Aggregation is the process of unification of the outputs of all rules. We take the membership functions of all rule consequents previously clipped and combined them into a single fuzzy set. Thus the input of the aggregation process is the list of clipped membership function and the output is one fuzzy set for each output variables. To get the highest value as a result, we use the max in the consequent, given the equation (7):

$$
\mu_{\mathrm{A} \cup \mathrm{B}}(\mathrm{x})=\max \left[\mu_{\mathrm{A}}(\mathrm{x}), \mu_{\mathrm{B}}(\mathrm{x})\right]
$$

The last step in fuzzy inference is defuzzification. Fuzziness helps evaluate the rules, but the final output of a fuzzy system has to be crisp number. The input for the defuzzification process is the aggregate output fuzzy set and the output is a single number. The technique used is centroid technique. It finds the point where a vertical line would slice the aggregate set into two masses. This centre of gravity (COG) can be expressed as

$$
\operatorname{COG}=\frac{\int_{2}^{b} \mu A(x) x d x}{\int_{2}^{b} \mu A(x) d x}
$$

\subsection{CONCLUSION}

This research is focused on fuzzy model in decision making system that works on determination of appropriate contact lenses based on information given by corneal topographer. The system is categorized as decision making system rather than intelligent system because the application is led to decision making than interact with the user. Therefore, the fuzzy data output from corneal topography will defined and selected the best solution from the user input. This system is tested with real data from National University of Malaysia Medical Centre. 
Inappropriate type of contact lenses will affect the comfort and safety of user. Therefore this system is developed to determine the suitable contact lenses based on the characteristic of patients cornea. In research of Alio, Claramonte, Caliz, Ramzy (2005) there is a case that patient could not wear contact lenses because of the intolerance or mechanical instability caused by irregularity of the corneal surface. That is the reason why this research is carried out so that the patient will not faced the future impact cause by inappropriate contact lens. This system determines and suggests whether a patient is suitable in using contact lens or glasses. This system would help user especially fitters or ophthalmologist to make decision on contact lenses usage in fast and accurate way.

\section{REFERENCES}

Alio, J.L., Claramonte, P.J., Caliz, A.,.Ramzy, M.I. (2005). Corneal Modeling of Keratoconus by Conductive Keratoplasty, Elsevier, 31, 190-197.

Arafeh, L., Singh, H. (1999). A Neuro Fuzzy Logic Approach to Material Processing, IEEE transactions on Systems, Man and Cybernatics- Part C: Application and Review, $29,362-370$.

Garavelli, A.C., Gorgoglione M., Scozzi, B. (1999). Fuzzy Logic to Improve The Robustness of Decision Support Systems Under Uncertainty. Computers and Industrial Engineering, 37, 477-480.

Gills, J.P. Corneal Topography. Retrieved November, 10, 2008, from http://www.stlukeslasik.com/html/patient education.html

Hong, X., Himebaugh, N., Thibos, L.N. (2001) On-Eye Evaluation of Optical Performance of Rigid and Soft Cotact Lenses, Optometri and Vision Science, 78, 872-880.

Keen, P.G. (1975). Computer-based Decision Aids: The Evaluation Problem. Sloan Management Review, 3, 140-166.

Kellogg Eye Center, The University of Michigan. Contact Lenses. Retrieved January, 20, 2008, from http://www.kellogg.umich.edu/patientcare/conditions/con tact.lenses.html.

Liu, Z., Huang, A.J., Pflugfelder, S.C. (1998). Evaluation of Corneal Thickness and Topography in Normal Eyes using the Orbscan Corneal Topography System. British Journal Online, 83,774-778.

Lu,F., Mao, X., Qu, J., Xu, D., He, J.C. (2003). Monochromatic Wavefront Aberrations in the Human Eye with Contact Lenses, American Academy of Optometry, 80, 135-141. 